\title{
Mice with Compromised 5-HTT Function Lack Phosphotyrosine-Mediated Inhibitory Control over Prefrontal 5-HT Responses
}

\author{
Nathalie M. Goodfellow, ${ }^{1 *}$ Derya Sargin, ${ }^{1 \star}$ Mark S. Ansorge, ${ }^{2}$ Jay A. Gingrich, ${ }^{2}$ and Evelyn K. Lambe ${ }^{1,3}$ \\ ${ }^{1}$ Department of Physiology, University of Toronto, Toronto, Ontario M5S 1A8, Canada, ${ }^{2}$ Department of Psychiatry, Columbia University, New York, New \\ York 10032, and ${ }^{3}$ Department of Obstetrics and Gynaecology, University of Toronto, Toronto, Ontario M5S 1A8, Canada
}

\begin{abstract}
The activity of the prefrontal cortex is essential for normal emotional processing and is strongly modulated by serotonin (5-HT). Yet, little is known about the regulatory mechanisms that control the activity of the prefrontal 5-HT receptors. Here, we found and characterized a deregulation of prefrontal 5-HT receptor electrophysiological signaling in mouse models of disrupted serotonin transporter (5-HTT) function, a risk factor for emotional and cognitive disturbances. We identified a novel tyrosine kinase-dependent mechanism that regulates 5-HT-mediated inhibition of prefrontal pyramidal neurons. We report that mice with compromised 5-HTT, resulting from either genetic deletion or brief treatment with selective serotonin reuptake inhibitors during development, have amplified 5-HT $1 \mathrm{~A}$ receptor-mediated currents in adulthood. These greater inhibitory effects of 5-HT are accompanied by enhanced downstream coupling to Kir3 channels. Notably, in normal wild-type mice, we found that these larger 5- $\mathrm{HT}_{1 \mathrm{~A}}$ responses can be mimicked through inhibition of Src family tyrosine kinases. By comparison, in our 5-HTT mouse models, the larger 5-HT $1 \mathrm{~A}$ responses were rapidly reduced through inhibition of tyrosine phosphatases. Our findings implicate tyrosine phosphorylation in regulating the electrophysiological effects of prefrontal 5 - $\mathrm{HT}_{1 \mathrm{~A}}$ receptors with implications for neuropsychiatric diseases associated with emotional dysfunction, such as anxiety and depressive disorders.
\end{abstract}

Key words: 5-HT transporter; 5-HT1a receptor; Kir3.1; prefrontal cortex; serotonin; tyrosine phosphorylation

\section{Introduction}

The prefrontal cortex constitutes the highest cortical level moderating emotional processing (Fuster, 2001). In freely behaving animals, single-cell in vivo recordings have demonstrated an intricate relationship between activity in prefrontal cortex and anxiety- and depressive-like behaviors (Adhikari et al., 2011; Warden et al., 2012). Because both prefrontal cortical activity and emotional processing are strongly modulated by serotonin (5HT), it is not surprising that disrupted prefrontal 5-HT signaling may participate in the pathophysiology of psychiatric diseases (Krishnan and Nestler, 2008). Yet, little is known about the cel-

Received Sept. 2, 2013; revised March 5, 2014; accepted March 28, 2014.

Author contributions: N.M.G., D.S., and E.K.L. designed research; N.M.G. and D.S. performed research;M.S.A. and J.A.G. contributed unpublished reagents/analytic tools; N.M.G. and D.S. analyzed data; N.M.G., D.S., M.S.A., J.A.G., and E.K.L. wrote the paper.

E.K.L. holds a Canada Research Chair (tier II) in Developmental Cortical Neurophysiology. This work was supported by the Natural Sciences and Engineering Research Council and the Province of Ontario (Early Researcher Award) to E.K.L. and Canadian Institutes of Health Research Banting and Best Canada Graduate Scholarship to N.M.G., M.S.A. and J.A.G. received support from National Alliance for Research on Schizophrenia and Depression, National Institute of Mental Health (Grant 2 R01 MH080116), and the Sackler Family. We thank Dr. Milton Charlton, Dr. Sabine Cordes, Dr. Paul Fletcher, and Dr. Mike Salter of the University of Toronto for constructive suggestions on the manuscript.

The authors declare no competing financial interests.

*N.M.G. and D.S. contributed equally to this work.

Correspondence should be addressed to Dr. Evelyn K. Lambe, Department of Physiology, University of Toronto, 1 King's College Circle, Toronto, Ontario M5S 1A8, Canada. E-mail: evelyn.lambe@utoronto.ca.

DOI:10.1523/JNEUROSCI.3762-13.2014

Copyright $\odot 2014$ the authors $\quad 0270-6474 / 14 / 346107-05 \$ 15.00 / 0$ lular mechanisms responsible for maintaining normal prefrontal 5-HT responses. It is also unknown whether such regulatory mechanisms are altered in individuals with biological vulnerabilities to developing psychiatric illness. Here, we used mouse models with disrupted serotonin transporter (5-HTT) function, a risk factor for emotional disturbances (Murphy and Lesch, 2008; Caspi et al., 2010), to investigate prefrontal 5-HT electrophysiological responses and their underlying cellular regulation.

\section{Materials and Methods}

Experimental animals. Experiments were performed in predominantly male adult ( $>$ P60) mice (and female mice, as specified) in accordance with animal protocols approved by University of Toronto. 5 -HTT ${ }^{+/+}$ (wild-type [WT]), 5-HTT ${ }^{+/-}$(heterozygous [HET]), or 5 -HTT ${ }^{-1-}$ (knock-out $[\mathrm{KO}]$ ) mice on a Sv129 genetic background were derived from heterozygous crossing (Lira et al., 2003; Ansorge et al., 2004). For postnatal treatments, WT Sv129 mice born in facility were randomly assigned to receive intraperitoneal injection of vehicle $(0.9 \% \mathrm{NaCl}, 5$ $\mathrm{ml} / \mathrm{kg}$ ), fluoxetine (FLX, $10 \mathrm{mg} / \mathrm{kg} ; 5 \mathrm{ml} / \mathrm{kg}$ ) (Ansorge et al., 2004), or no injection from P2-P11. For stress experiments, adult WT and HET mice were singly housed for at least 4 weeks (Matsumoto et al., 2005). Otherwise, mice were group-housed (2-4 per cage) under a 12:12 h light/dark cycles with ad libitum access to both food and water.

Electrophysiology. Coronal slices of medial prefrontal cortex (mPFC) were recorded in ACSF containing the following (in $\mathrm{mm}$ ): $128 \mathrm{NaCl}, 10$ D-glucose, $26 \mathrm{NaHCO}_{3}, 2 \mathrm{CaCl}_{2}, 2 \mathrm{MgSO}_{4}, 3 \mathrm{KCl}, 1.25 \mathrm{NaH}_{2} \mathrm{PO}_{4}, \mathrm{pH} 7.4$, and saturated with $95 \% \mathrm{O}_{2} / 5 \% \mathrm{CO}_{2}$ at $31^{\circ} \mathrm{C}-33^{\circ} \mathrm{C}$. Layer $\mathrm{V}$ pyramidal neurons were visualized using IR-DIC on an Olympus BX50WI micro- 
scope. Patch pipettes ( $3-5 \mathrm{M} \Omega$ ) contained the following (in $\mathrm{mM}$ ): 120 potassium gluconate, $5 \mathrm{KCl}, 2 \mathrm{MgCl}_{2}, 4 \mathrm{~K}_{2}$-ATP, $0.4 \mathrm{Na}_{2}$-GTP, $10 \mathrm{Na}_{2}-$ phosphocreatine, and 10 HEPES buffer, adjusted to $\mathrm{pH} 7.3$ with $\mathrm{KOH}$. Voltage-clamp recordings were performed at $-75 \mathrm{mV}$ using a Multiclamp 700B amplifier, filtered at $3 \mathrm{kHz}$, and digitized at $10 \mathrm{kHz}$. Analysis was performed using pClamp 10.2 software, and illustrated averaged traces were compiled using Axograph software. Serotonin currents were probed with bath application of 5-HT (10 $\mu \mathrm{M}$, unless stated otherwise). All drugs were obtained from either Sigma or Tocris Bioscience.

Immunohistochemistry. To visualize serotonergic fibers in $\mathrm{mPFC}$, we used mice that express eYFP only in serotonergic neurons and their processes (Zhao et al., 2011). These mice were crossed with $5-\mathrm{HTT}^{+/-}$ mice, and the resulting offspring were analyzed histologically. Brains were transcardially perfused with $4 \%$ PFA, cryoprotected in 30\% sucrose, and frozen before coronal cryostat sectioning $(30 \mu \mathrm{m})$. For immunostaining, three sections were taken from each mouse $(n=4$ mice per group). Free-floating sections were stained with rabbit anti-GFP (1:400, Invitrogen) and then incubated with anti-rabbit biotin-conjugated secondary antibody (Invitrogen) and streptavidin Alexa-488 (Invitrogen). Multiphoton imaging was performed using a Ti:sapphire laser (Mai Tai, Spectra Physics) at $780 \mathrm{~nm}$, and eYFP-positive 5-HT fibers were quantified as previously described (Grider et al., 2006).

Western blot. The mPFC was dissected and immediately frozen on dry ice. The tissue was lysed in ice-cold RIPA buffer $(150 \mathrm{~mm} \mathrm{NaCl}, 50 \mathrm{~mm}$ Tris- $\mathrm{HCl}, 40 \mathrm{~mm} \mathrm{NaF}, 5 \mathrm{~mm}$ EDTA, 5 mm EGTA, 1 mm sodium orthovanadate (OVD), $1 \%$ Igepal, $0.1 \%$ sodium deoxycholate, $0.1 \%$ SDS) supplemented with protease (Thermo Scientific) and phosphatase (Roche) inhibitors. Insoluble material was removed by centrifugation at $13,000 \mathrm{rpm}$ for $10 \mathrm{~min}$ at $4^{\circ} \mathrm{C}$. Protein concentration was measured using a Lowry-based method (Bio-Rad). For immunoblotting, $10-20 \mu \mathrm{g}$ protein was incubated at $70^{\circ} \mathrm{C}$ for $10 \mathrm{~min}$, separated by SDS-PAGE, transferred to a nitrocellulose membrane, blocked with $5 \%$ nonfat milk in Tween 20-Tris-buffered saline, and incubated overnight at $4^{\circ} \mathrm{C}$ in primary antibodies (rabbit anti-Kir3.1, 1:1000, Alomone; rabbit antiKir3.2, 1:1000, Alomone; rabbit anti-Kir3.4, 1:500, Alomone; rabbit anti-5- $\mathrm{HT}_{1 \mathrm{~A}} \mathrm{R}, 1: 1000$, Millipore Bioscience Research Reagents; rabbit anti-phospho-Src, 1:1000, Cell Signaling Technology; mouse anti-Src, 1:1000, Cell Signaling Technology; mouse anti-pY 1:1000, Millipore Bioscience Research Reagents; rabbit anti-GAPDH, 1:5000, Cell Signaling Technology). Immunoreactive bands were visualized using secondary antibodies coupled to HRP by ECL detection methods (Bio-Rad). Band intensities were analyzed relative to the loading control (GAPDH) using Bio-Rad Image Laboratory software.

Statistical analyses. All statistical analyses were performed with Prism 5 software and assessed for normality (D'Agostino and Pearson omnibus normality test) and variance. The $n$ values for electrophysiological experiments represent the number of recorded neurons (from at least 3 mice per group) and, for molecular experiments, represent the number of mice (repeated 3 times per mouse). All data shown are independent replicates; and for a subset of experiments, the experimenter was blind to 5-HTT genotype. In all datasets, we confirmed the significant effect of 5 -HTT manipulation on the 5-HT receptor current responses $(n=5$ independent replicates). Data with one independent variable were analyzed using $t$ test, paired $t$ test, repeated-measure one-way ANOVA (post hoc Bonferroni multiple-comparison tests), or nonparametric one-way ANOVA (Kruskal-Wallis test with Dunn's multiple-comparison tests). Analysis between two independent variables was performed using a twoway ANOVA. Data were expressed as mean \pm SEM and evaluated at a significance level of 0.05 .

\section{Results}

Serotonergic inhibition is enhanced in mice with constitutive or developmental 5-HTT disruption

Variations in the 5-htt gene have been suggested as a risk factor for emotional disturbance (Caspi et al., 2010), and reduced 5-HTT levels have been associated with increased stress- and anxiety-like behaviors in mice (Murphy and Lesch, 2008). To examine how 5-HTT alteration changes prefrontal cortex 5-HT
A
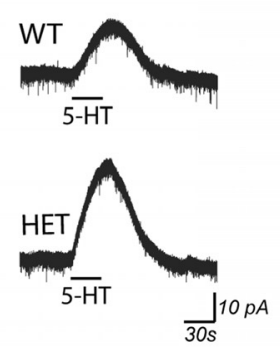

C

WT

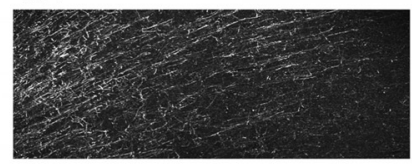

D

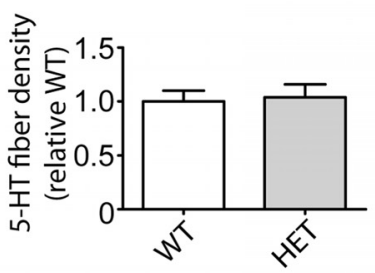

F

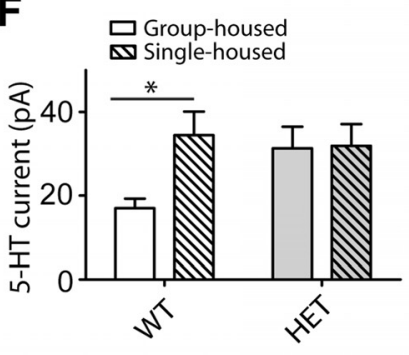

B

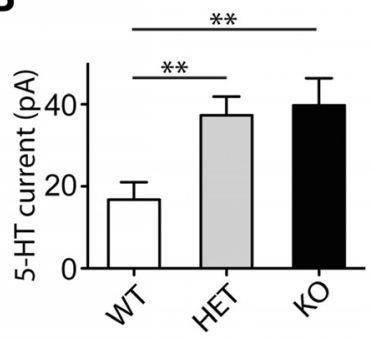

HET

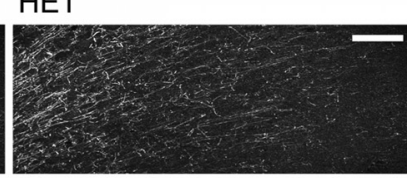

E

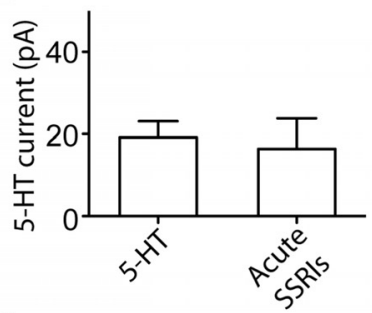

G

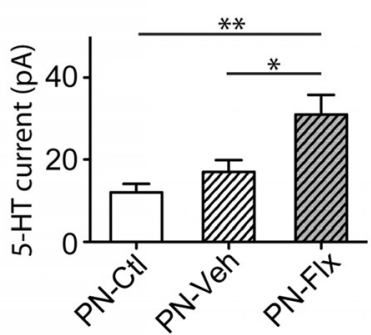

Figure 1. Constitutive or developmental 5-HTT disruption leads to amplified, inhibitory 5 -HT responses in prefrontal cortex. Averaged recordings $(\boldsymbol{A})$ and quantification $(\boldsymbol{B})$ of the outward currents elicited by 5-HT (10 $\mu \mathrm{M})$ in neurons from 5-HTT WT $(n=21)$, HET $(n=30)$, and $\mathrm{KO}(n=12)$ mice. Representative immunohistochemical staining $(\boldsymbol{C})$ and quantification (D) of eYFP-labeled 5-HT fibers in the medial prefrontal cortex. Scale bar, $25 \mu \mathrm{m}$. $\boldsymbol{E}$, The neuronal 5 -HT currents in the absence (baseline, $n=18$ ) or the acute presence of SSRIs (fluoxetine, $10 \mu \mathrm{M}, n=7$; citalopram, $10 \mu \mathrm{m}, n=6$ ) on WT brain slices $(p>0.05)$. $\boldsymbol{F}$, The 5 -HT currents in neurons from group-housed (WT, $n=20$; HET, $n=22$ ) or single-housed (WT, $n=21$; HET, $n=21$ ) mice. $\mathbf{G}$, Graph summarizing the 5 -HT currents from adult mice treated chronically during the postnatal period with the SSRI fluoxetine (PN-Flx, $n=15$ ), vehicle (PN-Veh, $n=$ 15), or control mice (PN-Ctl, $n=11)$. ${ }^{*} p<0.05$. ${ }^{* *} p<0.01$.

receptor activity, we performed whole-cell electrophysiological recordings in HET mice. Adult male HET mice displayed significantly larger inhibitory, outward, 5-HT current responses in prefrontal pyramidal neurons $(n=30)$, compared with neurons from littermate WT mice $(n=21 ; p=0.0002$, Mann-Whitney test; Fig. $1 A, B$ ). A similar amplification of the 5 -HT response was also present in neurons from mice with complete genetic deletion of 5-HTT (KO neurons, $n=12$; $p=0.002$, Mann-Whitney test; Fig. $1 B$ ), demonstrating that loss of one allele is sufficient to change the prefrontal 5-HT electrophysiological response. Similar amplified 5-HT responses were also observed in female HET mice (WT neurons, $n=22$; HET neurons, $n=22 ; p=0.005$, Mann-Whitney test). Combining males and females, the amplification represented a doubling of a near-maximal 5-HT response observed in the WT mice. The enhanced 5-HT responses 
in HET mice occurred in the absence of any discernible change in cortical 5-HT innervation ( $n=4 ; p=0.8$; unpaired $t$ test; Fig. $1 C, D)$ or change in 5 -HT levels or turnover in the prefrontal cortex (Bartolomucci et al., 2010). In WT brain slices, acute blockade of the 5-HTT with effective concentrations of selective serotonin reuptake inhibitors (SSRIs) (Rigdon and Wang, 1991) did not recapitulate the electrophysiological effects seen in the HET and KO mice (baseline, $n=18$, acute SSRI, $n=13 ; p=0.2$, Mann-Whitney test; Fig. 1E). Lack of amplification with acute 5-HTT inhibition was also replicated using a within-cell paired experimental design $(n=7 ; 108.0 \pm 10.2 \%$ baseline; $p=0.3$, paired $t$ test). Interestingly, a social isolation stress paradigm led to increased amplitude of the 5-HT outward current responses in WT mice (group-housed, $n=20$, single-housed, $n=21 ; p=$ 0.008 , unpaired $t$ test; Fig. $1 F$ ), similar to those observed in HET mice. However, in HET mice, social isolation did not further enhance 5-HT currents (group-housed, $n=22$, single-housed, $n=21 ; p=0.9$, unpaired $t$ test; Fig. $1 F$ ).

Given the prominent role of 5-HT in brain development (Lesch and Waider, 2012), we examined whether a limited disruption of 5-HTT during development was sufficient to potentiate prefrontal 5-HT electrophysiological responses in adulthood. To this end, we treated mice with fluoxetine (PN-Flx) during the early postnatal period, a time of transient developmental expression of 5-HTT in prefrontal cortex (Gaspar et al., 2003). We observed a significant amplification of the prefrontal 5-HT outward currents in neurons recorded from adult PN-Flx mice $(n=$ $15)$, compared with those from either PN-Vehicle $(n=15)$ or PN-Control mice $\left(n=11 ; F_{(2,38)}=7.1, p=0.002\right.$, one-way ANOVA; Fig. $1 G$ ). In short, disruption of 5-HTT function, either constitutively or transiently in development, but not acutely in slice, resulted in amplified, prefrontal 5-HT electrophysiological responses.

Mouse models of 5-HTT disruption display amplified 5-HT ${ }_{1 \mathrm{~A}}$ receptor currents with enhanced Kir3 downstream coupling Next, we examined the cellular origin and the receptor pathway underlying this amplified 5-HT response. Application of the voltage-gated $\mathrm{Na}^{+}$channel blocker tetrodotoxin did not alter the 5-HT current in HET mice, suggesting that the relevant 5-HT receptors are located on the recorded neurons $(n=5 ; 103.8 \pm$ $4.5 \%$ baseline; $p=0.5$, paired $t$ test). The potent and selective antagonist of $5-\mathrm{HT}_{1 \mathrm{~A}}$ receptors, WAY100635, abolished the 5-HT currents in both HET and PN-Flx neurons $(n=7 ; p=$ 0.0001 , paired $t$ test; Fig. $2 A, B$ ). This prefrontal amplification of $5-\mathrm{HT}_{1 \mathrm{~A}}$ receptor responses occurred in the absence of changes to protein levels of $5-\mathrm{HT}_{1 \mathrm{~A}}$ receptor (WT, $n=4$; $\mathrm{HET}, n=4 ; p=$ 0.9; Fig. 2C) or $\mathrm{G} \alpha_{\mathrm{i} / \mathrm{o}}$ in frontal cortex (Li et al., 2000).

Of note, potentiated postsynaptic $5-\mathrm{HT}_{1 \mathrm{~A}}$ receptor responses were accompanied by apparent changes to downstream effector channels. Whereas application of the Kir3 channel blocker tertiapin-Q significantly attenuated the $5-\mathrm{HT}_{1 \mathrm{~A}}$ receptor responses in both WT ( $n=6 ; p=0.04$, paired $t$ test) and HET neurons $\left(n=5 ; p=0.002\right.$, paired $t$ test), the $5-\mathrm{HT}_{1 \mathrm{~A}}$ responses from HET neurons were significantly more sensitive to tertiapin-Q (5-HTT genotype $\times$ tertiapin-Q interaction: $F_{(2,23)}$ $=5.7, p=0.009$, repeat-measures two-way ANOVA; Fig. 2D). This increased sensitivity to Kir3 blockade in HET mice emerged alongside a small but significant increase in the level of Kir3.1 protein in the prefrontal cortex (WT, $n=9$; HET, $n=10 ; p=$ 0.04, Mann-Whitney test; Fig. 2E). In contrast, protein levels of Kir3.2 (WT, $n=8$; HET, $n=8 ; p=0.6$, Mann-Whitney test; Fig. $2 F$ ) and Kir3.4 (WT, $n=8$; HET, $n=8 ; p=0.2$, Mann-Whitney
A

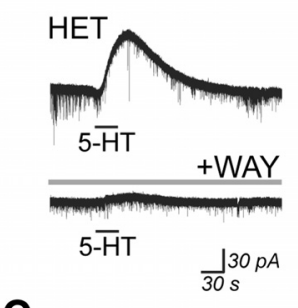

C

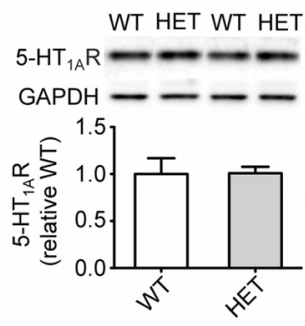

D

B
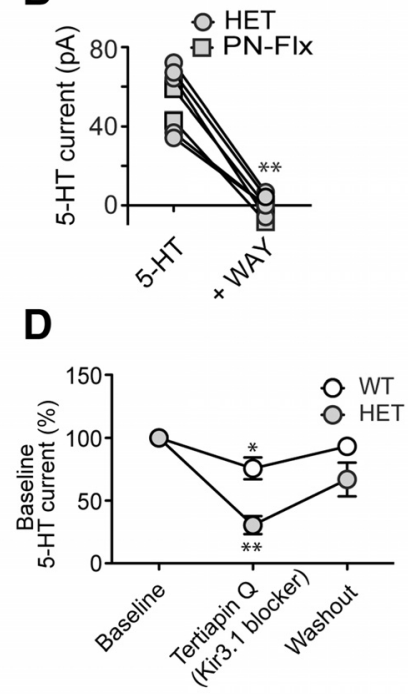

E

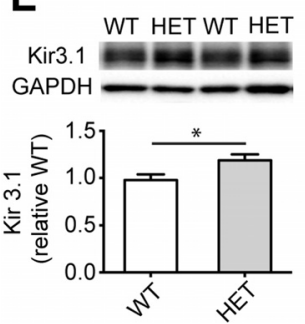

$\mathbf{F}$

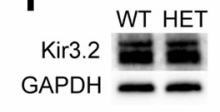

G
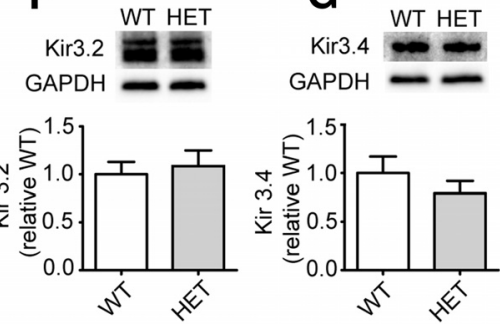

Figure 2. The $5-\mathrm{HT}_{1 \mathrm{~A}}$ receptor-Kir3 channel pathway mediates the amplified 5-HT electrophysiological response in mice with 5 -HTT disruption. Representative recordings $(\boldsymbol{A})$ and scatterplot $(\boldsymbol{B})$ of the $5-\mathrm{HT}$ response before and after application of the $5-\mathrm{HT}_{1 \mathrm{~A}}$ antagonist, WAY100635 (30 nM) in within-cell paired recordings from 5-HTT HET $(n=5)$ and PN-FIx $(n=$ 7) neurons. C, Representative Western blot (top) and quantification (bottom) showing prefrontal protein levels of $5-\mathrm{HT}_{1 \mathrm{~A}}$ receptor ( $n=4$ each group). $\boldsymbol{D}$, The $5-\mathrm{HT}_{1 \mathrm{~A}}$ current before and after application of the Kir3 channel blocker tertiapin $Q(0.1 \mu \mathrm{M})$ and washout $(10-20 \mathrm{~min})$ in neurons from WT $(n=6)$ and HET mice $(n=5)$. Representative Western blots (top) and quantification (bottom) showing prefrontal protein levels of Kir3.1 (E), Kir3.2 (F), and Kir3.4 (G) in WT $(n=8$ or 9$)$ and HET mice $(n=8-10) .{ }^{*} p<0.05 .{ }^{* *} p<0.01$.

test; Fig. $2 G$ ) subunits in the prefrontal cortex of HET mice were comparable with those of WTs. Together, these data indicate that mice with 5-HTT disruption display increased direct 5- $\mathrm{HT}_{1 \mathrm{~A}}$ receptor responses, which exhibit a greater coupling to the Kir3 channel pathway.

Tyrosine phosphorylation suppresses 5- $\mathrm{HT}_{1 \mathrm{~A}}$ currents in WT mice, but this mechanism is hindered in mice with 5-HTT disruption

The molecular mechanisms responsible for regulating normal prefrontal cortical $5-\mathrm{HT}_{1 \mathrm{~A}}$ receptor responses are not well understood. A candidate mechanism that can regulate signaling of other $\mathrm{G} \alpha_{\mathrm{i} / \mathrm{o}}$ protein-coupled receptors is tyrosine phosphorylation (Clayton et al., 2009). To test this mechanism in the prefrontal cortical brain slice, we first confirmed that we could significantly manipulate levels of tyrosine phosphorylation in this preparation $\left(F_{(2,9)}=50.7, p<0.0001\right.$, one-way ANOVA; ACSF baseline, $n=4)$ : a decrease with tyrosine kinase inhibition (PP2: $n=4 ; 69.9 \pm 10.4 \%$ baseline; $p<0.05$, Bonferroni's post hoc test) and an increase with tyrosine phosphatase inhibition (OVD: $n=4 ; 160.7 \pm 12.2 \%$ baseline; $p<0.001$, Bonferroni's post hoc test). In WT neurons, the $5-\mathrm{HT}_{1 \mathrm{~A}}$ responses were significantly potentiated by the general tyrosine kinase inhibitor, lav- 
A
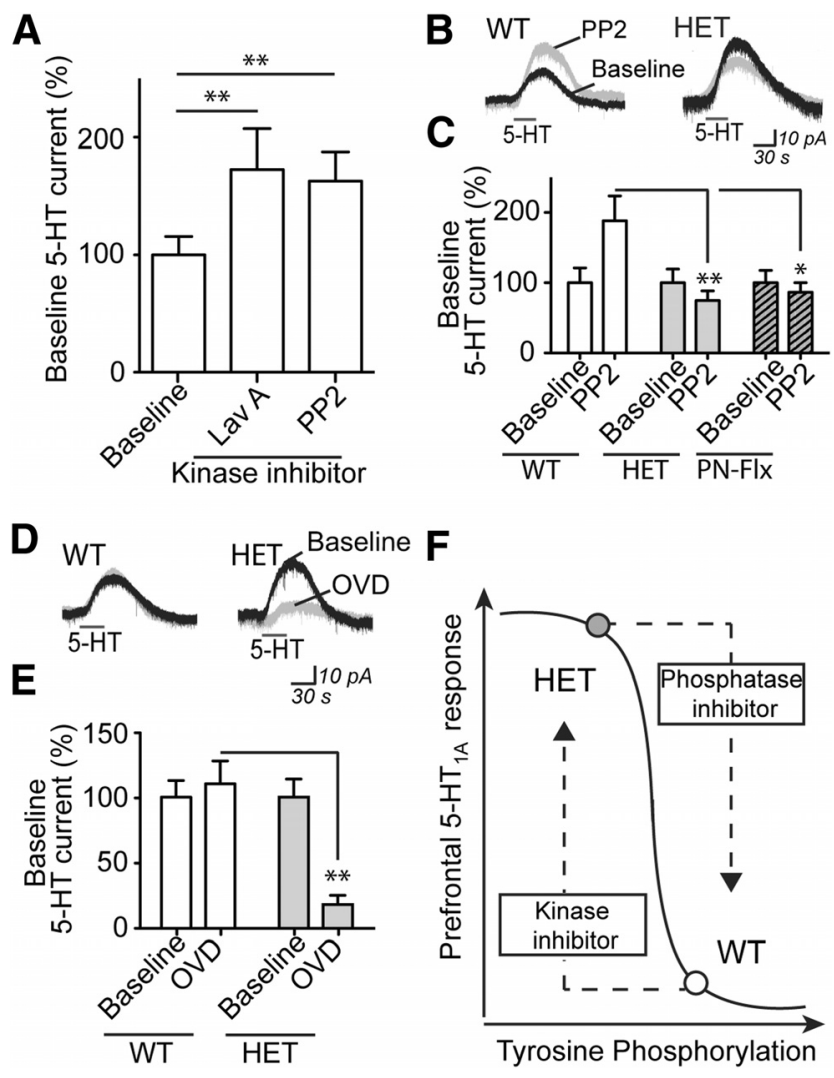

Figure 3. Inhibition of $5-\mathrm{HT}_{1 \mathrm{~A}}$ electrophysiological responses by tyrosine kinase activity is inefficient, but not lost, in mice with 5 - $\mathrm{HTT}$ disruption. $\boldsymbol{A}$, The $5-\mathrm{HT}_{1 \mathrm{~A}}$ responses from WT neurons in the absence (combined baseline, $n=51$ ) or presence of either tyrosine kinase inhibitors lavendustin A (10 $\mu \mathrm{M}$, Lav $A, n=19)$ or PP2 (10 $\mu \mathrm{M}, n=41)$. Averaged recordings $(\boldsymbol{B})$ and quantification $(\boldsymbol{C})$ of the $5-\mathrm{HT}_{1 \mathrm{~A}}$ response in the absence or presence of Src family tyrosine kinase inhibitor PP2 in neurons from WT (baseline, $n=22 ; \mathrm{PP} 2, n=17$ ), HET (baseline, $n=18 ; \mathrm{PP} 2$, $n=18$ ), and PN-FLX (baseline, $n=13 ; \mathrm{PP} 2, n=19$ ) mice. In graph, baseline-normalized data are shown to demonstrate that the effect of $P P 2$ differs significantly across groups. Independent replications of group differences in 5-HT response: WT versus HET or PN-FLX $(p<0.01)$. Averaged recordings $(\boldsymbol{D})$ and quantification $(\boldsymbol{E})$ of the $5-\mathrm{HT}_{1 \mathrm{~A}}$ responses in the absence or presence of tyrosine phosphatase inhibitor OVD (1 mM) from neurons of littermate WT (baseline, $n=25$; OVD, $n=20$ ) and HET (baseline, $n=13 ;$ PP2, $n=14$ ) mice. In graph, baseline-normalized data are shown to demonstrate that the effect of OVD differs significantly between groups. Independent replication of group difference in 5-HT response: WT versus HET ( $p=0.0001)$. $\boldsymbol{F}$, Schematic illustrating the working model of the relationship between prefrontal $5-\mathrm{HT}_{1 \mathrm{~A}}$ responses and tyrosine phosphorylation in 5-HTT WT and HET mice. ${ }^{*} p<0.05 .{ }^{* *} p<0.01$.

endustin A $(n=19)$, as well as by the more selective Src family kinase inhibitor, PP2 $(n=41 ; H=16.2, p=0.0003$, nonparametric one-way ANOVA; combined baseline, $n=51$; Fig. $3 A$ ). These findings were replicated in cell-paired experiments (lavendustin A: $n=6,146.2 \pm 12.4 \%$ baseline, $p=0.02$, paired $t$ test; PP2: $n=7,165.8 \pm 13.6 \%$ baseline, paired $t$ test, $p=0.002)$. By contrast, the WT $5-\mathrm{HT}_{1 \mathrm{~A}}$ responses were not altered by the inactive analogs: lavendustin $\mathrm{B}(n=15,99.5 \pm 23.4 \%$ baseline $)$ and PP3 $(n=20,107.7 \pm 22.7 \%$ baseline; $H=0.4, p=0.8$, nonparametric on-way ANOVA; combined baseline, $n=30$ ).

Next, we tested whether inhibiting tyrosine phosphorylation alters $5-\mathrm{HT}_{1 \mathrm{~A}}$ responses in $\mathrm{HET}$ and $\mathrm{PN}-\mathrm{Flx}$ mice and their sibling controls (5-HTT WT and PN-Control; Fig. $3 B, C$ ). There is replication of group differences in 5-HT currents and use of baseline-corrected data to emphasize the different consequences of decreased tyrosine phosphorylation across the groups. In this independent cohort of data, Src family kinase inhibitor PP2 again significantly potentiates the $5-\mathrm{HT}_{1 \mathrm{~A}}$ response in normal controls (baseline, $n=22$; PP2, $n=17 ; p=0.002$, Mann-Whitney test); however, it had no effect on $5-\mathrm{HT}_{1 \mathrm{~A}}$ electrophysiological responses in either HET neurons (baseline, $n=18$; PP2, $n=18$ ) or PN-Flx neurons (baseline, $n=13$; PP2, $n=19$; 5-HTT model $\times$ PP2 interaction: $F_{(2,101)}=4.1, p=0.02$, two-way ANOVA; Fig. $3 C)$. The absence of a PP2-induced potentiation in HET neurons was not the result of a ceiling effect, as a higher 5-HT concentration could elicit larger 5- $\mathrm{HT}_{1 \mathrm{~A}}$ currents in these neurons $(100 \mu \mathrm{M}$ 5-HT: $n=8,130.8 \pm 9.5 \%$ baseline; $p=0.02$, Wilcoxon signed rank test). Moreover, this difference in phosphotyrosinedependent regulation occurred in the absence of an effect of 5 -HTT genotype on protein levels of phosphotyrosine (pY, $p=$ 0.4 , unpaired $t$ test), Src ( $p=0.9$, unpaired $t$ test), or active, phosphorylated $\operatorname{Src}(\mathrm{pSrc}, p=0.6$, unpaired $t$ test) in the prefrontal cortex (WT, $n=5$; HET, $n=8$ ). These data suggest that prefrontal $5-\mathrm{HT}_{1 \mathrm{~A}}$ inhibitory responses are under regulatory control by Src family tyrosine kinases in WT mice but that this regulation is hindered in mice with altered 5-HTT function.

Finally, we examined whether blockade of tyrosine dephosphorylation could reduce $5-\mathrm{HT}_{1 \mathrm{~A}}$ responses in the prefrontal brain slice (Fig. $3 D, E$ ). Again, there are replication of group differences in 5-HT currents and use of baseline-corrected data to emphasize different OVD responses. Acute bath application of the tyrosine phosphatase inhibitor OVD had minimal effect on $5-\mathrm{HT}_{1 \mathrm{~A}}$ responses in WT neurons (baseline, $n=25$; OVD, $n=$ 20 ) yet dramatically attenuated the $5-\mathrm{HT}_{1 \mathrm{~A}}$ response in HET neurons (baseline, $n=13$; OVD, $n=14$; 5 -HTT model $\times$ OVD interaction: $F_{(1,68)}=35.4, p=0.003$, two-way ANOVA; Fig. $3 E$ ). Two additional tyrosine phosphatase inhibitors also significantly suppressed the $5-\mathrm{HT}_{1 \mathrm{~A}}$ responses in HET neurons (phenylarsine oxide: $n=11,7.2 \pm 4.7 \%$ baseline; bpV(phen): $n=8,29.1 \pm$ $12.6 \%$ baseline; $H=22.1, p<0.0001$, nonparametric on-way ANOVA; combined baseline, $n=28$ ), findings that were replicated in within cell-paired experiments $(n=7 ; 38.3 \pm 10.9 \%$ of baseline; $p=0.004$, paired $t$ test). Yet in WT neurons, tyrosine phosphatase inhibitors did not elicit a significant suppression of the current (baseline, $n=15$; phenylarsine oxide: $n=10,73.1 \pm$ $20.8 \%$ baseline; $p=0.2$, unpaired $t$ test). Last, in HET neurons, this strong reduction of $5-\mathrm{HT}_{1 \mathrm{~A}}$ currents after treatment of tyrosine phosphatase inhibitors could be prevented if slices were pretreated with the Src family kinase inhibitor, PP2 (PP2 + OVD: $n=15,120.4 \pm 35.1 \%$ baseline; $p=0.2$, Mann-Whitney test; baseline, $n=13$ ).

The implications of these findings are twofold (Fig. $3 F$ ). First, our findings reveal a novel role of tyrosine phosphorylation in the regulation of the $5-\mathrm{HT}_{1 \mathrm{~A}}$ receptor electrophysiological responses in WT mice. Second, they suggest that, in neurobiologically vulnerable 5-HTT mouse models, the amplified 5- $\mathrm{HT}_{1 \mathrm{~A}}$ receptor responses result from inefficient phosphotyrosine-dependent control. Yet, as indicated by the phosphatase inhibition experiments, this regulatory mechanism is not lost.

\section{Discussion}

Our results demonstrate amplified prefrontal $5-\mathrm{HT}_{1 \mathrm{~A}}$ receptor electrophysiological responses alongside enhanced coupling to downstream effector Kir3 channels in mouse models of 5-HTT disruption. In humans, $5-\mathrm{HT}_{1 \mathrm{~A}}$ receptors are ideally positioned to mediate top-down control of neural networks (Hahn et al., 2012) and in rodents are thought to be essential for normal emotional behaviors (Ramboz et al., 1998). Disrupting 5-HTT activity has been associated with a range of consequences, including differences in anxiety, aggression, and depressive-like behavior (for review, see Murphy and Lesch, 2008). Yet, it remains contro- 
versial whether disruption of the 5-HTT-function alone is sufficient to induce behavioral pathology either in humans or in rodents. Instead, a "two-hit" model has been proposed where disruptions to the 5-HTT may need to be compounded with an environmental insult, such as stress, in order for a behavioral phenotype to emerge (Caspi et al., 2010; Lesch, 2011; Carola and Gross, 2012). For example, chronic stress has more pronounced behavioral effects on 5-HTT deficient mice compared with WT mice (Bartolomucci et al., 2010; Nietzer et al., 2011). Here, we found that social isolation stress increased prefrontal $5-\mathrm{HT}_{1 \mathrm{~A}}$ receptor currents in WT mice, making them similar to the currents in group-housed 5-HTT deficient mice. Yet, single housing did not further increase the $5-\mathrm{HT}_{1 \mathrm{~A}}$ outward currents in the latter mice, suggesting that prefrontal 5-HT inhibition may reach a ceiling effect. Alternatively, if prefrontal 5- $\mathrm{HT}_{1 \mathrm{~A}}$ currents are normally flexible to amplification by a "hit" on the system, the lack of such flexibility observed in mice with perturbed 5-HTT may contribute to their vulnerability to stress in adulthood.

Here, we found that manipulation of tyrosine phosphorylation can have rapid effects on 5-HT inhibition of prefrontal pyramidal neurons but that these effects are strikingly different in WT mice compared with mouse models with 5-HTT disruptions. A number of proteins associated with the $5-\mathrm{HT}_{1 \mathrm{~A}}$ receptor pathway are potentially subject to such modulation, including members of the $G_{\alpha / \beta \gamma}$ effector pathway (Luttrell and Luttrell, 2004), Kir3.1 channel subunits (Clayton et al., 2009), and essential scaffolding molecules (Kleene et al., 2010). Future work is necessary to identify the tyrosine residues essential in controlling prefrontal $5-\mathrm{HT}_{1 \mathrm{~A}}$ inhibition and to explore further the behavioral implications of manipulating 5-HT inhibition in this manner. We show, for the first time, that a phosphotyrosine-dependent mechanism regulates normal prefrontal $5-\mathrm{HT}_{1 \mathrm{~A}}$ inhibition, that this phenomenon is programmed in development, and that it is impeded in mouse models of disrupted 5-HTT.

\section{Notes}

Supplemental material for this article is available at http://individual. utoronto.ca/Lambe_Lab/. This material has not been peer reviewed.

\section{References}

Adhikari A, Topiwala MA, Gordon JA (2011) Single units in the medial prefrontal cortex with anxiety-related firing patterns are preferentially influenced by ventral hippocampal activity. Neuron 71:898-910. CrossRef Medline

Ansorge MS, Zhou M, Lira A, Hen R, Gingrich JA (2004) Early-life blockade of the 5-HT transporter alters emotional behavior in adult mice. Science 306:879-881. CrossRef Medline

Bartolomucci A, Carola V, Pascucci T, Puglisi-Allegra S, Cabib S, Lesch KP, Parmigiani S, Palanza P, Gross C (2010) Increased vulnerability to psychosocial stress in heterozygous serotonin transporter knockout mice. Dis Model Mech 3:459-470. CrossRef Medline

Carola V, Gross C (2012) Mouse models of the 5-HTTLPR $\times$ stress risk factor for depression. Curr Top Behav Neurosci 12:59-72. CrossRef Medline

Caspi A, Hariri AR, Holmes A, Uher R, Moffitt TE (2010) Genetic sensitivity to the environment: the case of the serotonin transporter gene and its implications for studying complex diseases and traits. Am J Psychiatry 167:509-527. CrossRef Medline

Clayton CC, Xu M, Chavkin C (2009) Tyrosine phosphorylation of Kir3 following kappa-opioid receptor activation of p38 MAPK causes heterologous desensitization. J Biol Chem 284:31872-31881. CrossRef Medline

Fuster JM (2001) The prefrontal cortex-an update: time is of the essence. Neuron 30:319-333. CrossRef Medline

Gaspar P, Cases O, Maroteaux L (2003) The developmental role of serotonin: news from mouse molecular genetics. Nat Rev Neurosci 4:10021012. CrossRef Medline

Grider MH, Chen Q, Shine HD (2006) Semi-automated quantification of axonal densities in labeled CNS tissue. J Neurosci Methods 155:172-179. CrossRef Medline

Hahn A, Wadsak W, Windischberger C, Baldinger P, Höflich AS, Losak J, Nics L, Philippe C, Kranz GS, Kraus C, Mitterhauser M, Karanikas G, Kasper S, Lanzenberger R (2012) Differential modulation of the default mode network via serotonin-1A receptors. Proc Natl Acad Sci U S A 109: 2619-2624. CrossRef Medline

Kleene R, Cassens C, Bähring R, Theis T, Xiao MF, Dityatev A, SchaferNielsen C, Döring F, Wischmeyer E, Schachner M (2010) Functional consequences of the interactions among the neural cell adhesion molecule NCAM, the receptor tyrosine kinase TrkB, and the inwardly rectifying K+ channel KIR3.3. J Biol Chem 285:28968-28979. CrossRef Medline

Krishnan V, Nestler EJ (2008) The molecular neurobiology of depression. Nature 455:894-902. CrossRef Medline

Lesch KP (2011) When the serotonin transporter gene meets adversity: the contribution of animal models to understanding epigenetic mechanisms in affective disorders and resilience. Curr Top Behav Neurosci 7:251-280. CrossRef Medline

Lesch KP, Waider J (2012) Serotonin in the modulation of neural plasticity and networks: implications for neurodevelopmental disorders. Neuron 76:175-191. CrossRef Medline

Li Q, Wichems C, Heils A, Lesch KP, Murphy DL (2000) Reduction in the density and expression, but not G-protein coupling, of serotonin receptors (5-HT1A) in 5-HT transporter knock-out mice: gender and brain region differences. J Neurosci 20:7888-7895. Medline

Lira A, Zhou M, Castanon N, Ansorge MS, Gordon JA, Francis JH, BradleyMoore M, Lira J, Underwood MD, Arango V, Kung HF, Hofer MA, Hen R, Gingrich JA (2003) Altered depression-related behaviors and functional changes in the dorsal raphe nucleus of serotonin transporterdeficient mice. Biol Psychiatry 54:960-971. CrossRef Medline

Luttrell DK, Luttrell LM (2004) Not so strange bedfellows: G-protein-coupled receptors and Src family kinases. Oncogene 23:7969-7978. CrossRef Medline

Matsumoto K, Pinna G, Puia G, Guidotti A, Costa E (2005) Social isolation stress-induced aggression in mice. Stress 8:85-93. CrossRef Medline

Murphy DL, Lesch KP (2008) Targeting the murine serotonin transporter: insights into human neurobiology. Nat Rev Neurosci 9:85-96. CrossRef Medline

Nietzer SL, Bonn M, Jansen F, Heiming RS, Lewejohann L, Sachser N, Asan ES, Lesch KP, Schmitt AG (2011) Serotonin transporter knockout and repeated social defeat stress: impact on neuronal morphology and plasticity in limbic brain areas. Behav Brain Res 220:42-54. CrossRef Medline

Ramboz S, Oosting R, Amara DA, Kung HF, Blier P, Mendelsohn M, John Mann JJ, Brunner D, Hen R (1998) Serotonin receptor 1A knockout: an animal model of anxiety-related disorder. Proc Natl Acad Sci U S A 95: 14476-14481. CrossRef Medline

Rigdon GC, Wang CM (1991) Serotonin uptake blockers inhibit the firing of presumed serotonergic dorsal raphe neurons in vitro. Drug Dev Res 22:135-140. CrossRef

Warden MR, Selimbeyoglu A, Mirzabekov JJ, Lo M, Thompson KR, Kim SY, Adhikari A, Tye KM, Frank LM, Deisseroth K (2012) A prefrontal cortex-brainstem neuronal projection that controls response to behavioural challenge. Nature 492:428-432. CrossRef Medline

Zhao S, Ting JT, Atallah HE, Qiu L, Tan J, Gloss B, Augustine GJ, Deisseroth K, Luo M, Graybiel AM, Feng G (2011) Cell type-specific channelrhodopsin-2 transgenic mice for optogenetic dissection of neural circuitry function. Nat Methods 8:745-752. CrossRef Medline 